\title{
Ultradisperse slag suspensions aggregative and sedimentative stability
}

\author{
Svetlana Samchenko ${ }^{1}$, Olga Zemskova ${ }^{1}$, and Irina Kozlova ${ }^{1}$ \\ ${ }^{1}$ Moscow State University of Civil Engineering, Yaroslavskoe shosse, 26, Moscow, 129337, Russia
}

\begin{abstract}
Ultradisperse slag suspensions in aqueous and water-polymer phases have been studied. Disperse systems main stability factors applied to the ultradisperse slag have been considered. Chemical equations for the processes running in the aqueous and water-polymer disperse phases with slag particles have been provided. Graphical dependencies confirming the increase of the aggregative stability and sedimentative stability of the ultradisperse slag suspensions have been illustrated, and the processes causing such an increase have been disclosed.
\end{abstract}

\section{Introduction}

The studies of the cement stone containing the carbon nanotubes (CNT) stabilized suspension obtained by acoustic cavitation method demonstrate high performance [1-4], which allows to consider the CNT concentrate as one of the components for the mortar preparation in structural and thermally insulated aerated concrete production.

However, the industrial-scale use of the CNT in the construction material production is very limited today.

Ultradisperse blast furnace granulated slags (UBFGS) may serve as one of the CNT alternatives.

Performance of the cement stone depends on how evenly the ultradisperse slag particles are distributed within the binder matrix, that is why it is recommended to add them to the binding compositions in the form of aqueous suspensions. Owing to that, the studies of the aggregative and sedimentative stability is topical.

\section{Experimental}

During the course of this study, we have used the blast furnace granulated slag (Nizhny Tagil, Sverdlovsk Oblast) milled in the LHL-1 laboratory jet mill to the $1 \mathrm{mcm}$ size particles.

Chemical composition and granulometric composition of the slag are provided in table 1 and 2. Ultradisperse slag have been used to prepare the suspension out of it, where the slag content is $1 \%, 3 \%, 5 \%(10 \mathrm{~g} / 1,30 \mathrm{~g} / 1,50 \mathrm{~g} / \mathrm{l})$ per $100 \mathrm{~cm}^{3}$.

\footnotetext{
*Corresponding author: ov.zemskova@yandex.ru
} 
Table 1. Slag chemical composition

\begin{tabular}{|c|c|c|c|c|c|c|}
\hline \multirow{2}{*}{ Material } & \multicolumn{6}{|c|}{ Oxides content, \%w } \\
\cline { 2 - 7 } & $\mathrm{CaO}$ & $\mathrm{SiO}_{2}$ & $\mathrm{Al}_{2} \mathrm{O}_{3}$ & $\mathrm{MgO}$ & $\begin{array}{c}\mathrm{Fe}_{2} \mathrm{O}_{3}+ \\
\mathrm{FeO}\end{array}$ & Other \\
\hline $\begin{array}{c}\text { Blast furnace } \\
\text { granulated slag }\end{array}$ & 45.40 & 38.20 & 8.10 & 3.20 & 0.8 & 4.30 \\
\hline
\end{tabular}

Table 2. Slag granulometric composition

\begin{tabular}{|c|c|c|c|c|c|c|c|}
\hline \multirow{2}{*}{ Material } & \multicolumn{7}{|c|}{ Fractions, \%w } \\
\cline { 2 - 8 } & $0-0.5$ & $0.5-1$ & $1-1.5$ & $1.5-2$ & $2-3$ & $3-4$ & $4-5$ \\
\hline $\begin{array}{c}\text { Blast furnace } \\
\text { granulated slag }\end{array}$ & 8.21 & 30.44 & 23.35 & 17.2 & 11.77 & 5.89 & 3.14 \\
\hline
\end{tabular}

UBFGS refers to the basic slags, since the slag basicity factor Mo amounts to 1.1. The calculation has been accomplished using the formula:

$$
M_{o}=\frac{\mathrm{CaO}+\mathrm{MgO}}{\mathrm{SiO}_{2}+\mathrm{Al}_{2} \mathrm{O}_{3}}=\frac{45,40+3,20}{38,20+8,10}=1,1
$$

The tap water $(\mathrm{pH}=7.6)$ and the tap water with polycarboxylate resin ester superplasticizer have been used as the disperse phases; their general formula is:

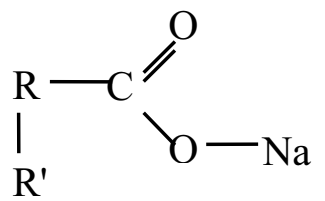

UBFGS suspensions have been prepared using the mechanical stirring by magnetic mixer for $5 \mathrm{~min}$. Ready-to-use ultradisperse slag suspensions with the corresponding concentrations have been poured into the $100 \mathrm{~cm}^{3}$ cylinders in order to observe the sedimentation, while the time period from the suspension preparation beginning to the particles intensive sedimentation completion, disperse phase clarification completion, and reaching absolutely clear disperse phase have been measured.

\section{Evaluation}

During the course of the aggregative, and so the sedimentative stability of the UBFGSwater \& UBFGS-water-plasticizer systems, it has been determined that the UBFGS sedimentation process with $1 \%, 3 \%, 5 \%$ particles concentration may be divided into three periods of sedimentation (fig. 1):

1-st period - particles intensive sedimentation: most of the slag particles settle, less than $1 \mathrm{mcm}$ UBFGS particles remain suspended in the disperse phase;

2-nd period - disperse phase clarification: less than $1 \mathrm{mcm}$ particles settle, these may be referred to as sols;

3-rd period - UBFGS particles sedimentation processes completion: the disperse phase becomes absolutely clear. 


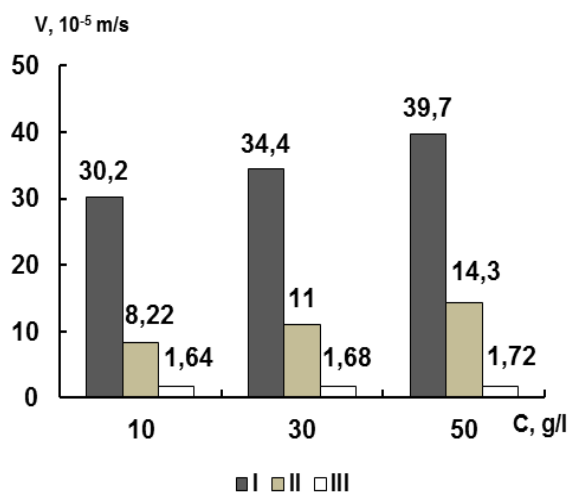

a

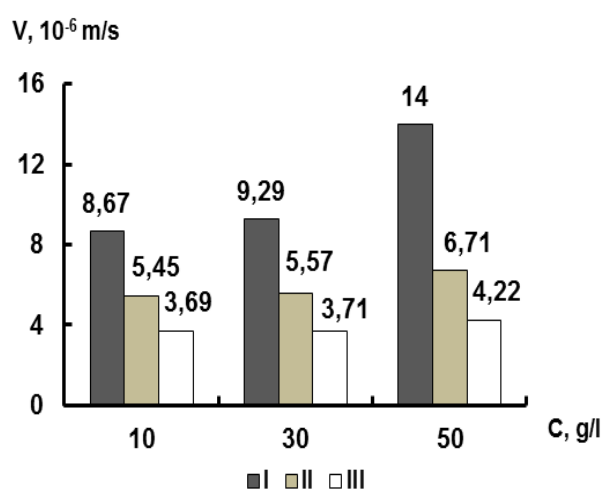

$\mathrm{b}$

Fig. 1 Particles sedimentation rate vs. UBFGS concentration in the 1-st, 2-nd, and 3-rd particles sedimentation periods: $\mathrm{a}$ - no stabilizer; $\mathrm{b}$ - with superplasticizer stabilizer. V - particles sedimentation rate, $\mathrm{m} / \mathrm{s} ; \mathrm{C}$ - UBFGS concentration, $\mathrm{g} / \mathrm{l}$

Aggregative stability of slags in aqueous phase is stipulated by the hydrolysis and hydration processes running in contrast to aggregative stability of aqueous suspension carbon nanotubes and fullerene C60 [5-6].

UBFGS that have been used in these studies refers to the basic slags (basicity modulus 1.1 , with prevailing content of basic orthosilicates, mostly dicalcium silicate $2 \mathrm{CaO} \cdot \mathrm{SiO}_{2}$ $\left(\mathrm{Ca}_{2} \mathrm{SiO}_{4}\right)[7]$.

When the slag is added to water, hydrolysis and hydration processes occur as expressed by the following chemical equation:

$$
2\left(2 \mathrm{CaO} \cdot \mathrm{SiO}_{2}\right)+3 \mathrm{H}_{2} \mathrm{O}=3,3 \mathrm{CaO} \cdot 2 \mathrm{SiO}_{2} 2,3 \mathrm{H}_{2} \mathrm{O}+0,7 \mathrm{Ca}(\mathrm{OH})_{2}
$$

or

$$
\mathrm{Ca}_{2} \mathrm{SiO}_{4}+2 \mathrm{H}_{2} \mathrm{O}=\mathrm{CaH}_{2} \mathrm{SiO}_{4}+\mathrm{Ca}(\mathrm{OH})_{2}
$$

In the aqueous disperse phase, the UBFGS particles are surrounded by the water dipoles, which adsorb on their surface, while the electrolytic disintegration of water occurs forming the $\mathrm{H}^{+}$(or hydroxonium $\mathrm{H}_{3} \mathrm{O}^{+}$) and $\mathrm{OH}^{-}$ions. $\mathrm{OH}^{-}$ions interact with $\mathrm{Ca}^{2+}$ contained in the slag and convert them to mixture forming the $\mathrm{Ca}(\mathrm{OH})^{+}$ions [7].

$\mathrm{H}^{+}$ions attach to the $\mathrm{SiO}_{4}{ }^{4^{-}}$tetrahedron, which leads to formation of the reaction products surface layer consisting of the silicic acid ion groups with various acidity ( $\mathrm{HSiO}_{4}{ }^{3^{-}}$, $\left.\mathrm{H}_{2} \mathrm{SiO}_{4}{ }^{2-}, \mathrm{H}_{3} \mathrm{SiO}_{4}{ }^{-}\right)$on the UBFGS surface. At the same time, the slag particle $\left(\mathrm{Ca}_{2} \mathrm{SiO}_{4}\right)$ becomes negatively charged. On the surfaces between phases, double electric layer is formed, which in combination with the disperse phase forms the slag micelle.

UBFGS micelle (micelle 1) may be written in the following manner:

$$
\left\{\left(\mathrm{Ca}_{2} \mathrm{SiO}_{4}\right)_{m} n \mathrm{SiO}_{4}^{4^{-}} 4(n-x) \mathrm{H}^{+}\right\}^{4^{-}} \cdot 4 x \mathrm{H}^{+}
$$

As the reaction goes, the UBFGS surface accumulates the reaction products, and the mixture gradually becomes saturated with $\mathrm{Ca}^{2+}$ and $\mathrm{OH}^{-}$ions. Resulting $\mathrm{Ca}^{2+}$ ions with greater charge and size in comparison with $\mathrm{H}^{+}$ion, replace the latter - according to what we assume, in the diffuse and adsorption layer, and penetrate to the colloid particles surface with active spots, thus stipulating the chemisorption process. Hence, the chemisorption on 
the slag surface initiates with the $\mathrm{Ca}^{2+}$ movable ions and silicate ions of the UBFGS stationary surface.

Excess of the $\mathrm{Ca}^{2+}$ ions becomes the potential-forming one, and the slag surface becomes positively charged.

From now on, the UBFGS micelle (micelle 2) looks as follows:

$$
\left\{\left(\mathrm{Ca}_{2} \mathrm{SiO}_{4}\right)_{m} n \mathrm{Ca}^{2+} 2(n-x) \mathrm{OH}^{-}\right\}^{2+} \cdot 2 x \mathrm{OH}^{-}
$$

Most of the colloid particles whose counter-ions are $\mathrm{H}^{+}$ions (micelle 1) remain negatively charges owing to the lack of active centers on their surface.

Thus, in the UBFGS-water system two types of micelles have been formed (micelle 1, micelle 2), in which the colloid particles have negative and positive charge respectively. Availability of the double electric layer in colloid particles determines the aggregative and sedimentative stability of the UBFGS-water system thanks to the electrostatic factor.

The studies of the UBFGS aggregative and sedimentative stability in the aqueous disperse phase have demonstrated the following: the higher the slag particles concentration is, the quicker their sedimentation process is during all three periods of sedimentation (fig. 1a). This is explained by the fact that under the same conditions the particles with higher concentration more frequently collide to each other and the cylinder walls. When colliding with each other, the counter-ions spontaneously move from the diffuse layer to the adsorption layer. Herewith, molecular adhesion forces become dominating. The thickness of the diffuse layer reduces, the energy barrier weakens, which leads to the system coagulation and, correspondingly, to quicker gravitational sedimentation. Suspension becomes thermodynamically unstable and settles [8-11].

To use the ultradisperse slags suspensions efficiently in the construction industry, it is necessary to boost their stability during the 1-st period, during the intensive sedimentation of the particles. To do that, the stabilizing agent, the polycarboxylate superplasticizer, have been added to the slag-water system; this stabilizer essentially is the anionic long-chain surfactant [12-13]. To determine the concentration required for protection of the ultradisperse slag suspensions against the coagulation, 0.1-0.5 $\mathrm{g}$ of the surfactant has been added per $100 \mathrm{ml}$ of suspension containing $5 \%$ of UBFGS. Consequently, the following mixtures have been obtained, where the superplasticizer content amounted to 1-5 g/l. Suspensions prepared have been poured into the $100 \mathrm{~cm}^{3}$ cylinders to observe the complete sedimentation process of the UBFGS stabilized suspensions. Protection value of the $S$ suspension has been calculated using formula:

$$
S=\frac{C \cdot V_{1}}{\mathrm{~V}}
$$

where $\mathrm{C}$ - concentration of the stabilizer mixture, $\mathrm{g} / \mathrm{l} ; \mathrm{V}_{1}$ - volume of the stabilizer mixture to protect the suspension against the coagulation, $\mathrm{ml}$; $\mathrm{V}$ - suspension volume, ml. Results of the experiment are illustrated in table 3.

Table 3. UBFGS suspension aggregative stability ( $\mathrm{W}=5 \%)$

\begin{tabular}{|l|c|c|c|c|c|}
\hline \multirow{2}{*}{ Parameter } & \multicolumn{5}{c|}{ Cylinder No. } \\
\cline { 2 - 6 } & 1 & 2 & 3 & 4 & 5 \\
\hline Stabilizer concentration, g/l & 1 & 2 & 3 & 4 & 5 \\
\hline Suspension S protection value, $* 10^{-3} \mathrm{~g} / \mathrm{l}$ & 1 & 4 & 9 & 16 & 25 \\
\hline $\begin{array}{l}\text { UBFGS sedimentation completion time, h- } \\
\text { min. }\end{array}$ & $4-20$ & $5-50$ & $7-00$ & $10-00$ & $10-20$ \\
\hline
\end{tabular}

According to the data provided in table 2, it may be derived that the UBFGS-water system is stable to the maximum extent when the polycarboxylate superplasticizer is added 
to it using the $4 \mathrm{~g}$ per 11 of the suspension. This amount of stabilizer is recommended for use in further studies.

To consider the physical and chemical processes running in the UBFGS-water and UBFGS-water-stabilizer systems, the $\mathrm{pH}$ value of the disperse phase has been measured in the suspensions with $1 \%, 3 \%, 5 \%$ particles concentration (table 4 ).

Table 4. Disperse phase $\mathrm{pH}$

\begin{tabular}{|c|c|c|c|}
\hline No. & Disperse phase & UBFGS, $\%$ & pH \\
\hline 1 & \multirow{4}{*}{ water } & no additives & 7.60 \\
\hline 2 & & 1 & 7.80 \\
\hline 3 & & 3 & 7.88 \\
\hline 4 & & 5 & 8.08 \\
\hline 5 & \multirow{4}{*}{ water + superplasticizer } & no additives & 7.92 \\
\hline 6 & & 1 & 8.22 \\
\hline 7 & & 3 & 8.37 \\
\hline 8 & & 5 & 8.40 \\
\hline
\end{tabular}

According to table 4, when the plasticizing agent is added to water, the disperse phase becomes more basic. This confirms that the superplasticizer used is of anionic nature.

Interaction between the UBFGS and the plasticizer in the aqueous phase follow the chemical equation:

$$
\mathrm{Ca}_{2} \mathrm{SiO}_{4}+\underset{\mathrm{l}}{\mathrm{R}-\mathrm{COONa}+\mathrm{HOH}=\mathrm{CaHSiO}_{4}-\mathrm{OCO}-\underset{\mathrm{l}}{\mathrm{R}}+\mathrm{NaOH}}
$$

where R - non-polar radical of the main chain; R' - non-polar radical of the side chain.

When added to the UBFGS-water system, the superplasticizer dissociates in water forming the surface active anions, functional carboxylic groups $\mathrm{R}-\mathrm{COO}$.

On the slag particles surface the adsorption processes begins, which is accompanied by the fixing of the functional carboxylic groups. Herewith, the particle surface becomes negatively charged, and the $\mathrm{H}^{+}$ions are in the diffuse layer. Double electric layer is formed with the superplasticizer involved. This occurs on the slag colloid particles that are positively charged only, since the superplasticizer is the anionic superplasticizer. From now on, the UBFGS micelle (micelle 3) looks as follows:

$$
\left\{\left(\mathrm{Ca}_{2} \mathrm{SiO}_{4}\right)_{m} \underset{\mathbf{l}^{\prime}}{\left.n R-\mathrm{COO}^{-}(n-x) H^{+}\right\}^{-} \cdot x H^{+}}\right.
$$

The forming of the adsorption layer at the colloid particles is influenced by the main HC chain directed away from them, and the side $\mathrm{HC}$ chain forming the additional spatial (steric) stability effect. Furthermore, the same radicals form strong and elastic gel-like films on the ultradisperse slap particles surface, thus enhancing the structural \& mechanical factor of the aggregative stability. Superplasticizer, which is an anionic long-chain surfactant, is also adsorbed on the disperse phase particles surface, lyophilizes it, and may facilitate the forming of the solvate layer. Therefore, when the superplasticizer is added to 
the UBFGS suspension, the adsorption-solvate, electrostatic, and structural \& mechanical factors of the aggregative stability are functioning.

When the superplasticizer agent (polycarboxylate resin ester superplasticizer) is added to the UBFGS-water system, the aggregative stability of such system increases (fig. 1b). Herewith, the tendency to the slag suspensions maximum stability with their minimal concentration is retained [14-17].

When comparing the aggregative stability of the ultradisperse slag particles in the aqueous and water-polymer disperse phases, it has been determined that in presence of the superplasticizer the UBFGS-water system becomes more stable: during the 1-st period, $\times 33.3$ times in average; during the 2 -nd period, $\times 18.7$ times in average; during the 3 -rd period, $\times 4.3$ times in average. The maximum effect in the slag particles stabilization has been achieved during the 1-st period of their sedimentation (fig. 1a, b).

Therefore, the research accomplished has demonstrated that the polycarboxylate resin ester superplasticizer ensures high aggregative and sedimentative stability for the UBFGS aqueous suspensions, which facilitates even distribution of the slag particles within the cement composite when mixing the suspension with the dry bonding material. Application of the ultradisperse slags stabilized suspensions allows to obtain the cement stone with improved structural and physical \& mechanical performance.

\section{Conclusions}

1. It has been established that there are three periods of sedimentation available in the UBFGS-water and UBFGS-water-stabilizer systems with $1 \%, 3 \%$, and $5 \%$ particles concentration.

2. Possibility to form and possibility of existence of the two types of micelles in the UBFGS-water system has been theoretically substantiated:

Micelle $1\left\{\left(\mathrm{Ca}_{2} \mathrm{SiO}_{4}\right)_{\mathrm{m}} \mathrm{nSiO}_{4}{ }^{4-} 4(\mathrm{n}-\mathrm{x}) \mathrm{H}^{+}\right\}^{4-} \cdot 4 \mathrm{xH}^{+}$;

Micelle $2\left\{\left(\mathrm{Ca}_{2} \mathrm{SiO}_{4}\right)_{\mathrm{m}} \mathrm{nCa}^{2+} 2(\mathrm{n}-\mathrm{x}) \mathrm{OH}^{-}\right\}^{2+} \cdot 2 \mathrm{xOH}^{-}$

3. Existence of Micelles 1 and 2 stipulates the availability of double electric layer that ensures the aggregative and sedimentative stability in the UBFGS-water system by means of electrostatic factor.

4. The studies of the UBFGS aggregative and sedimentative stability in the aqueous disperse phase have demonstrated the following: the higher the slag particles concentration is, the quicker their sedimentation process is during all three periods of sedimentation.

5. It has been established that in order to preserve the aggregative and sedimentative stability in the UBFGS-water system, it is necessary to use the polycarboxylic resin ester superplasticizers amounting to $4 \mathrm{~g}$ per 1 of the suspension.

6. Possibility to form and possibility of existence of the micelle in the UBFGS-waterstabilizer system has been theoretically substantiated:

$$
\text { Micelle } 3\left\{\left(\mathrm{Ca}_{2} \mathrm{SiO}_{4}\right)_{\mathrm{m}} \mathrm{nR}_{\mathrm{I}}^{\left.\mathrm{R}-\mathrm{COO}^{-}(\mathrm{n}-\mathrm{x}) \mathrm{H}^{+}\right\}^{-} \cdot \mathrm{xH}^{+}}\right.
$$

7. Existence of Micelles 3 ensures the aggregative and sedimentative stability in the UBFGS-water-stabilizer system by means of electrostatic, adsorptive-solvatic, and structural-mechanical factors of the aggregative stability and steric effect that arise from the involvement of the main chain and side chain of the superplasticizer.

8. Thanks to the high aggregative and sedimentative stability of the UBFGS waterpolymer suspensions, it is possible to achieve the even distribution of the slag particles within the cement composite volume, and make the cement stone with improved structural and physical \& chemical performance. 


\section{References}

1. S. Samchenko, O. Zemskova, I. Kozlova, Russ. J of Appl. Chem., 87, 1872 (2014)

2. S. Samchenko, O. Zemskova, I. Kozlova /, Cement-Wapno-Beton., XX / LXXXII, $322(2015)$

3. S.Samchenko, O. Zemskova, I. Kozlova, Silicates Technics and Technologies, 21, 14 (2014)

4. S. Shekhovtsova, M. Vysotskaya, Vestnik of MGSU, 110 (2015)

1. 5 E. Zakharychev, M.Kabina,E.Razov ,Colloid Jornal, 78, 556 (2016)

5. V. Tseluikin, Colloid Jornal, 78, 668 (2016)

6. T. Kuznetsova, S. Samchenko, Cement Production Materials Microscopy (2007)

7. L. Molodkina, E.Golikova, R. Bareeva, A. Chysov, N.Bogdanova, Colloid Jornal, 78, 578 (2016)

8. A. Malova, A.Grodskii, I.Belova, Colloid Jornal, 78, 478 (2016)

9. A. Volkova, E.Golikova, LErmakova, N.Bogdanova, L. Molodkina, Colloid Jornal, 76, 395 (2014)

2. 11.E. Reshetnyak, O. Chernysheva, N. Mchedlov-Petrosyan, Colloid Jornal,78, 602 (2016)

3. 12. Sh. Baran, R. Mesaroshm R. Taubaeva, K. Musabekov, Colloid Jornal, 77, 698 (2015)

4. 13. A. Sobolev, Colloid Jornal, 77, 364 (2015)

5. 14. A. Rusanov, Colloid Jornal, 78, 613 (2016)

6. 15. A. Rusanov, Colloid Jornal, 78, 671 (2016)

7. 16. A. Rusanov, Colloid Jornal, 78, 88 (2016)

8. 17. T. Movchan, A. Rusanov, T. Plotnikova, Colloid Jornal, 78, 750 (2016) 